\title{
Exploring the Unity Practices of School Leaders in Malaysian Secondary Schools
}

\author{
Bity Salwana A ${ }^{1}$, Nuraidah $R^{1}$, Mohd Radzi I . ${ }^{1}$, Maslawati $M^{{ }^{*}}$ \\ ${ }^{1}$ Faculty of Education, Universiti Kebangsaan Malaysia, Bangi, Selangor, Malaysia, 43600 \\ * Corresponding author: maslawati@ukm.edu.my \\ bity@ukm.edu.my; nuraidah@ukm.edu.my;radzi.ishak@moe.gov.my; maslawati@ukm.edu.my \\ ORCID ID Maslawati Mohamad https://orcid.org/0000-0002-8979-5895
}

Article History: Received: 10 November 2020; Revised 12 January 2021 Accepted: 27 January 2021; Published online: 5 April 2021

\begin{abstract}
This qualitative study was embarked with the aim of exploring school leaders' practices in enhancing unity among Malaysian secondary school leaders. The instrument used for collecting data involved visiting the participated schools in order to conduct individual face-to-face interviews involving 12 participants who are secondary school leaders (principals and senior assistants). The data were analyzed manually. The findings showed that school leaders have not yet fully played their role to instill the 10 values of unity as proposed in the Model of Unity. The policy on unity emphasized by school leaders is only the usage of Malay Language. However, findings showed that in order to enhance unity, school leaders will remind teachers and students about unity in school gathering and meeting. School leaders will also remind multi-racial teachers and students to celebrate all the festivals, to participate in school activities, to respect each other in terms of cultural and religious differences, to instill unity values during school activities, to avoid sensitive issues and to be fair to all races. The managerial implication is school leaders need to do more practices to enhance unity. Therefore, they need more training to understand better the 10 values of unity, and to get knowledge and skills to inculcate values effectively. The findings of this study could benefit readers on the activities that they could employ to enhance unity in their institution.
\end{abstract}

Keywords: Practices to enhance unity; Unity model; School leaders; Secondary schools; Values.

\section{Introduction}

Unity in diversity is often used as an expression to describe the harmony between different individuals or groups [1]. [2] state that the concept of unity over diversity among group members should not be restricted to ensure unity. On the contrary, racial conflict remains one of the major problems in current social life [3,4,5]. According to [6], almost everyday school leaders in England and elsewhere face race-related problems. Racism is also a problem in America's urban schools [7,8]. In South Africa, although transition from a racially stratified education system to unified non-racist provision has dramatically changed the policy context for school [9], cultural background and religion different contribute significantly in promoting bullying behaviour in schools [10]. As a multi-racial country with three major races namely Chinese, Indian and Malay, and hundreds of ethnic groups, unity is a challenge to Malaysian government as well. [11] states that unity in Malaysia is a social situation where people from various ethnic groups, religious beliefs and regional areas live together peacefully as one nation. Effort to enhance unity were apparently made [12]. However, several recent incidents of racial tensions have raised a public question on Malaysia unity level [13]. Studies conducted by Malaysian Ministry of Education, MoE shows that unity level is decreasing $[13,14,15,16]$. Even though the differences in the native language, religions and cultural practices, politics ideologies could be the reasons for a low or moderately unity level. [17] statement that educational institutions have a significant role to overcome inter-racial prejudice whether through the curriculum, human resource policy, practices or systems used, and [18] statement that principals are uniquely positioned to either promote or undermine equity in their schools raised a question whether school leaders' practice could be the reason for the decline to occur. Many actions have been taken through the education system to nurture positive values among multiracial students [16] such as upholding the Malay language as the language of unity, using the same curriculum and examination in all schools, launching Student Integration Plan for Unity, implementing vision school, and empowering national schools. Malaysian Government has also launched Malaysia Education Blueprint (PPPM) 2013-2025 on November 11, 2012 with strengthening unity being stated as one of the key initiatives. In conjunction to that, in 2018, MOE has also launched School Unity Practice Guidelines and implementing Unity Course for School Leaders to ensure school leaders could play their roles effectively in promoting unity. The MoE policies and guidelines raised another important question: how far school leaders have played their role in enhancing unity. However, very limited studies have been done to answer this question [16]. Therefore, there are two significance of this study. First, realizing the research gap in terms of literature - what are the practices of the school leaders in enhancing unity in Malaysia, this research was embarked. 
Second, the findings from this study could help the MoE to design better content to train school leaders on the effective activities they could carry out in their schools to enhance unity among multiracial students in Malaysia. This study found that school leaders have carried out few practices to enhance unity which include emphasizing on the usage of Malay Language, reminding school teachers and students about unity during school assemblies and meetings, encouraging multicultural festivals celebration and respecting cultural diversity and religious practices, incorporating unity elements in the implementation of school activities, encouraging involvement of multicultural members in school activities, taking precautions to avoid racial sensitivity and control conflicts among races, and being fair to all races.

This paper proceeds as follows. First, it provides a generic overview of the concept of unity and the importance of school leaders' role in promoting unity. After presenting the research methodology, the result analysis and discussion are presented, followed by the implications and conclusions.

\section{Literature Review}

National Unity and Integration Department of Malaysia stated that unity exists when a country is at peace without conflict among races. Based on this statement, it looks like Malaysia has achieved unity, while citizens live happily without any fear. However, [19] Shamsul Amri stated that in Malaysia, unity does not yet exist. He highlighted, what is happening in Malaysia is only a process of social cohesion where people of various races tolerate and avoid negative feelings towards one another. These different views of unity are might be caused by different definition of unity. In 2014, based on their research, Malaysia Ministry of Education (MOE) through one of the Division that is Educational Policy and Research Division (EPRD), had come out with a clear definition of unity. The definition is explained through a Model of Unity for teachers and students. The model states that, unity is a result, while teachers and students from multiple races are able to accept, respect and manage their differences in terms of culture, native language and religious practices. As shown in Figure 1, the model shows that to be able to accept, respect, and manage differences, teachers and students need to possess a list of unity values that are, openness, tolerance, teamwork, trust, prudence, appreciative, caring, fair, trustworthy, and rationale.

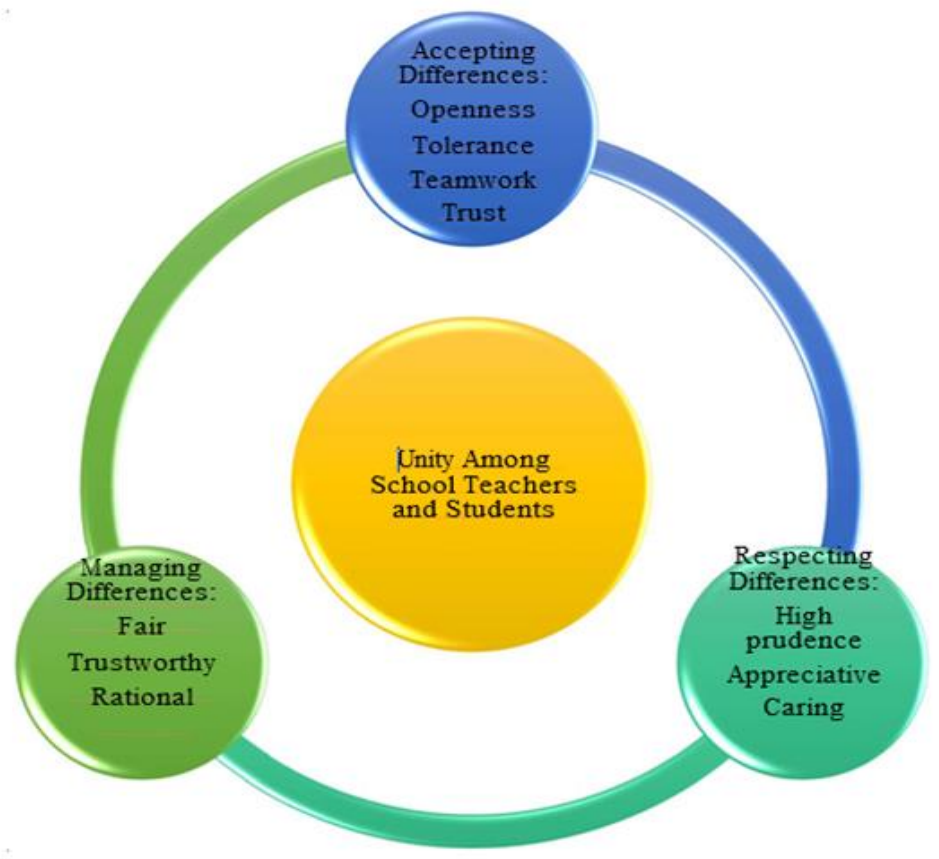

FIGURE 1. Unity Model for School Teachers and Students (Ministry of Education Malaysia, 2014)

Based on the model, EPRD, MoE has developed instrument to measure unity. The measurement was done in 2014, 2016, and 2018. The result showed that unity level is decreasing. The factor for the decreasing is not yet studied. However, there is a possibility that one of the factors is school leaders' role. The assumption is based on the action done by MoE to introduce guidelines for unity in school and to train school leaders on unity [16].

The actual fact is leaders can play their role to persuade peoples to unite [20]. [21,17, 22] that leadership is a process of persuading or influencing others, in which a leader or a group of leaders influence their subordinates to take an action that can achieve the leaders or organizational goal. [23] has the same opinion, by saying that leaders and followers is a group of people who can interact, communicate and influence each other in achieving a common goal, and in this context to unite. There is no doubt that school leaders can change behaviours of 
teachers and students, as being said by [24], that leadership is a process of influencing others toward a change of behaviours. The goal of unity must be shared by school leaders to all teachers and students. It is as an act to achieve organizational goal that is shared collectively and engage all members of an organization [25]. In Malaysian context, school leaders have a power to influence one's behavior to the extent that he or she is willing to cooperate with others in order to achieve an agreed goal [19] that is unity a high level.

There are a few more discussion on the relationship between leadership and unity. [26] in her article titled 'Empowering Unity' stated that leaders should try to use common terms associated with unity to ensure the objectives of unity and peaceful coexistence could be achieved. Terms like tolerance, harmony, goodwill and diversity must be mutually understood and should bring the same meaning to all races. [26] also stated that leaders' statements and speeches always become a signal to their subordinates on the actions that they must take. Therefore, responsible leaders will put attempts to minimize chaos and factors that could destroy the stability of the society. They should use their position to strengthen relationship and promote unity among all races. On the other hand, Sabariah, a member of Malaysia Media Literacy Research team (2018), in her paper titled 'Ensuring Peace and Unity', wrote that many efforts have been done to forge national unity in Malaysia. Besides involving all races in implementing programs, Sabariah also suggested that good conduct, integrity, ethics and honesty (National Principles or Rukun Negara) are important values that Malaysians should uphold to ensure peace and unity.

According to [10], unity can be enhanced through language, sport and festivals. In his paper titled 'How to forge National Unity', he stated that after 56 years of independence, there is no excuse for ordinary Malaysians of all races not to be fluent in Bahasa Malaysia, the national language. In other words, he believes that by mastering Malay language, unity can be enhanced. He further explained that sports could bring citizens of all races sit together under one common platform. He also suggested that the culture of 'Open House' during festival celebrations should be encouraged. He stated that the festive seasons bring a true message of unity to all Malaysians. Seng's opinion is supported by the Penang State Consultative Goodwill Council [27], which stated that the spirit of unity must be instilled constantly in all programs. Therefore, activities such as football competitions, walkathons, seminars and other events in which all the ethnics could take part should be organized. Other views by [28], proposed that in order to enhance national unity, focus must be given on the 4Rs and 4Ms. In his paper titled, 'Promoting National Unity and Harmony', Michael stated that the 4Rs (respect, reciprocity, responsibilities of citizenship, and racial and religious tolerance) and the 4Ms (moderation, morality, mechanisms to overcome conflicts, and middle Malaysia standing up for unity and harmony) are requirement to overcome conflicts. Michael also emphasized that the values of acceptance, compromise and tolerance to enhance trust and confidence must be enhanced. He added that national harmony can be further enhanced if policies are fair, just and inclusive. [29] looking at unity from a different angle. He wrote that unity is an important component of managing any successful organization. Accordingly, she proposed five steps to enhance unity that are developing a common goal, organizing team-building activities, encouraging open communication, celebrating important events, and solving any arising issues.

Most of the discussion above showed that there is strong influence of leaders' practices towards unity among the school community. The findings of these past studies confirmed the Unity Model proposed in this study. Unity among Malaysians could be achieved if teachers and students possess 10 values of unity. Apparently, these values could lead to the ability to accept, respect and manage culture, language and religious practices differences. The findings of past studies also emphasize that school leaders still need to attend training or courses to increase their knowledge about unity values that are openness, tolerance, teamwork, trust, prudence, appreciative, caring, fair, trustworthy, and rationale. Consequently, such knowledge on the unity values could increase their awareness and skills to enhance unity among school community. However, empirical studies to show the practices of school leaders in Malaysia in strengthening unity are still very scarce. Therefore, this study was embarked with two objectives: (1) to reduce the literature gap and (2) to develop relevant content for training the school leaders.

\section{Methodology}

According to [30,31, 32, 33, 34, 35], research design is a specific planning methods or procedures to collect and analyse data based on research questions. To run parallel with the purpose of exploring the practices of school leaders, this study used a survey design with qualitative approach to collect data. The samples are 12 school leaders from all over Malaysia. Data saturated shows that the interviewed samples are enough for the study [30]. As a qualitative study, the instrument is interview protocol [36] that consists of 16 questions to explore school leaders' practices in enhancing unity. The education policies [16] and the Unity Model [17] are the main reference in developing research instrument. The interview questions are to explore school leaders' practices in enhancing unity by encouraging teachers and students to accept, respect and manage differences among them [16]. In addition, the researchers tried to obtain information whether school leaders have instilled the unity value as stated in Unity Model [16]. Interview questions and protocols were standardized for both categories of respondents: (1) 
school leaders from government schools and (2) school leaders from religious schools.

In order to ascertain the reliability and validity, a few measures have been carried out. In order to ascertain the content validity, the researchers gave the interview questions to be validated by six experts in the area, including academicians in educational leadership and policy and experience MoE officers who directly involved in planning and implementing policy to enhance unity through education. The experts checked whether the interview questions are correct and suitable. In other words, the interview questions enable the researchers to obtain the answers for the designed research question: what are the school leaders' practices in strengthening unity? This is due to the fact that no such research has been done to give the answer to this question. The next measure to ascertain the reliability and validity of the interview questions. During the pilot study, the interview questions were being tested in four schools. The eight school leaders from government and religious schools that are located at both urban and rural areas have given their opinions to improve the interview protocol. Amendments were made on the interview questions based on the respondents' feedback during the pilot study before they were being used for the actual study. The comments from the respondents therefore served as input to improve the interview protocol as well.

Purposive sampling was used to obtain respondents for this study. The selection criteria were geographical locations (urban and rural areas) and types of school (government schools and religious schools). Three schools were selected from the rural areas and three schools from the urban areas. While, for school types, two ordinary government schools and one religious' school from each geographical location were selected.

After getting the MoE officers' approval to conduct the study and collect the data, the researchers went to the selected schools to interview 12 secondary school leaders who are principals and/or senior assistants. Pseudonym was given to the school leaders, P for the school principals and PK for the senior assistants. In every school, two school leaders were interviewed via face-to-face according to their convenient time and place. The interview session was handled by two researchers: prime researcher and her research assistant. The purpose is to ensure that the researcher could focus on the interview questions, whereas, the research assistant could take note the interview responses while recording the session. The length of the interview is between 45 minutes to 1 hour depending on the respondents' responses. The recorded in interview responses were transcribed in verbatim. The transcriptions were returned to the respondents for respondent validation. The respondents could make amendments on the transcriptions to ensure the transcriptions were done accurately. The interview responses have captured their actual responses - feelings, practices and opinions.

For analysis procedure, firstly, data were transcribed in verbatim. The data then being analysed manually by all the research team members. There were three data coders analysing the data. Collaboratively, they counterchecked the themes and coding that appeared from the data.

\section{Results/Findings}

The analysis was done based on the research question, "What are school leaders' practices in strengthening unity? Findings showed that, even though school leaders not emphasized much on the implementation of education policy related to unity except for the usage of Malay language, and not clearly emphasized on the ability of teachers and students to accept, respect and manage differences, which also means not fully instilled the 10 values of unity as stated in the Unity Model [16], there are few practices done by school leaders to strengthen unity as follows:

a) Emphasizing on the usage of Malay Language

Result showed that to enhance unity, school leaders encouraged teachers and students to use Malay language whether for official events or for their daily conversation, as said by PK8:

"The use of the Malay language in school is greatly emphasized... Malay language fully utilized in school conversation, in all events and in daily conversation..." (PK8)

Even in a school with three main languages for daily conversation, the usage of Malay language is still emphasized. This is based on what has been said by P4:

"Malay language is the language for unity and it is embedded in our education system. As far as I am concerned, we have a national interest ... besides the second language, English and Arabic. When it comes to SMKA, all the three languages are used ... but most of the time, we use a national language..." (P4)

If there are students who are not fluent in Malay language, school leaders still emphasize the usage by placing them in a class with multi-racial students. This is explained by PK2:

“... We always remind each other to speak Malay language... we place new students from SJKC in a class that is not only with one race. They will be placed in class with multiracial students to ensure that they use Malay language to interact..." (PK2)

b) Reminding the school community on unity during school assemblies and meetings

To show that unity is being focused, school leaders have reminded and explained about unity during school 
assemblies and meetings, as said by P4, PK2, and PK3:

"Unity are always our focus... especially in weekly gatherings and in teacher meetings... we will explain about unity elements and talk about the importance of unity... I will speak and we will not forget to include the value of unity..." (P4)

"During teachers' meeting, he reminded about unity... In school assembly he will explain the matter..." (PK2)

"We can see in official assembly on Monday... we are reminded by the principal about the unity, in socializing and communicating..." (PK3)

To show his concern on unity, P6 has included unity element in students vow during assembly:

"This year I changed a bit student vows in assembly... There are words of preservation, harmony and unity as the sixth or seventh point in the pledge..." (P6)

PK8 not only remind about unity during assembly, but also remind teachers and students to accept and respect each other. Teachers and students also being reminded to mix around in order to unite:

“...principals always remind us to respect, to care and to be polite to each other... Principals always remind teachers and students, especially during assembly... he reminds us to accept and respect cultural differences ... no issue on religion practices in this school... students were emphasized that they need to mix around... not just among their own group..." (PK8)

c) Celebrating multicultural festivals and respecting cultural diversity and religious practices

School leaders' practices to strengthen unity is include celebrating multi-racial festivals in school and respect religious rituals of other races as stated by $\mathrm{P} 2$ :

"... we do not prevent other races to engage with their own activities... there is no issue for the Muslims to celebrate their activities in the mosque... no issues for the Christian teachers and students to spend half an hour in prayer..." (P2)

Other practices are joining festivals together as said by P5, P7, and PK8:

"...we are trying to join Chinese New Year and Hari Raya... for the new year, teachers give their full support... students, although many of them are Kadazan, I can see the unity... they are open to each other." (P5)

"Sometimes Chinese New Year and Hari Raya close to each other... we celebrate both together... students and teachers come with their own festive attire... unity in terms of food ... we have multiracial performance... we do have activities to foster unity." (P7)

"...we celebrate all the festivals together...All teachers understand and respect each other... we allow non-

Muslim to perform their ritual as long as not against school regulations. ... if Indian teacher is vegetarian, we take care of it... we celebrate Chinese New Year together... For Hari Raya, all students wear their national attire... Indian and Chinese teachers here, they will buy one for them..." (PK8)

Permissions are also given to teachers and students to practice their own cultural and religious practices. The statement of PK4 is as follows:

“...for non-Muslim teachers, if they want to celebrate Eastern Monday... principal gives them a permission... Muslim students, we give permission for them to go for Friday prayer... during fasting month, non-Muslim students were not allowed to eat in public... (PK4)

d) Incorporating unity elements in the implementation of school activities

Another practice is school leaders ensured that all school activities have the elements of unity. Teachers were reminded to instill unity values during their teaching and learning, during co-curricular activities and in implementing school programs, and even in writing essay competition. This conclusion is based on P1, P6, PK1, and PK3 statements:

“...we practice unity in many forms ... elements of unity need to be incorporated into every school activity... at least one of the objectives in each program related to unity." (P1)

"...student will create a unity mural on the school walls as an annual project... one of the ways to incorporate the value of unity through subject... we do discuss how to practice value of unity in school... it can be done not just in activities called unity... It can also be done through sport activity ... It can even be applied through academic activities..." (P6)

"...counsellors always talk about the value of unity, the value of openness... one of the ways to expose them to other races is by having essay competition about unity..." (PK1)

"... school activities can foster unity... let say camping... they have to be together for 3 days ... at the end of the day, good relationships have been established..." (PK3)

In religious schools, school leader consider Islamic values is the pillar of unity. Therefore, they just emphasized teachers and students to practice the Islamic values. These statements are derived from PK4 statement:

"We apply unity values... students are reminded to respect teachers... to have a close relationship with students and teachers... of any race or religion... we apply admirable personalities... Unity is going to be one aspect of the core values of religion... Islam is a religion of unity." (PK4) 
Encouraging involvement of multicultural members in school activities

Practices of school leaders in strengthening unity includes inviting communities of various races to participate in school activities. This conclusion is derived from the statements by P1, P3, and P6:

"...if we organize school activity, we invite nearby school... for the festivals and sports...we invite community as well..." (P1)

"...for our sports tournament, we have collaboration with PIBG and community... we have created a

networking... The target is to unite our diverse students..." (P3)

“...To implement Student Integration Plan for Unity Program, as a religious school, we invite other schools of different races and religions...we tried to get multiracial companies to involve in our activities... we do arrange academic visit to companies... there is an element of unity in it. We invite PIBG to involve..." (P4)

"We do have engagement with outsiders... PIBG... school activities aim for unity... in any celebration... PIBG will always involve... Department of National Unity used to come to our school and did their activities here... they invite our students to join their program. The purpose is to enhance interaction..." (P6)

For the religious school with homogeneous students (all Malays), school leaders will invite other races students from near-by school to join their program as explained by PK1 and PK4:

“...we started the collaboration... we organize a game and invite other school to join... the school have Chinese and Indian... they have multiracial students... the students have fun in sports... that's the easiest way to mix... the purpose is to know each other, they will enjoy the game, win or lose, no matter..." (PK1)

"...We do implement Student Integration Plan for Unity Program between schools. We go to other schools. Nearby schools have Chinese and Iban... in our school, it is quite difficult to do the program because we have one race students..." (PK4)

On the other hand, PK8 ensure that whatever program launched by school, it must involve student from all races, as said by PK8:

“... what we do is to get involvement from all races... if we organize a Camp for Excellence, we involve all... if we have to choose students to represent our school for the tournament... like sports activities... everyone will get involve... (PK8)

f) Taking precautions to prevent activities that negatively affect school community sensitivity and control conflicts among races

Avoiding sensitivities issues and preventing any inter-racial conflicts are also school leaders' practices in strengthening unity. This is based on P2 statement:

"I will make sure that exam questions are not sensitive... nothing touches racism... I emphasize to teachers and students that no non-halal or sensitive food in the school... even in the teacher's room, must ensure taking care of others sensitivity..." (P2)

Action also being taken to stop the culture of bully and racial strife. Any conflicts would be resolved almost instantly. Responses regarding these are as follows:

"Normally, we would remind for the gathering, celebrations and so on... no bullying between different races... If not, they would be in big problems because it is racist..." (P5)

"....in the context of student affairs... a little bit of it involves multi-racial clashes ... we call the heirs ... the discipline committees ... there are various races among the teachers ... to simplify the heirs ... we end all the conflict at the school level...." (PK3)

"We always remind students and teachers ... any issue arise, must be resolved immediately... often Indian students' bully other students... teachers must put on eyes on this matte... (PK8)

g) Being fair and give equal opportunities for all members

Being fair to all teachers and students regardless of their race are the practices of school leaders to strengthen unity. For example, equal opportunities are given to teachers to receive rewards or recognition. This is based on the P1, P2, P5, PK1, and PK3 statements:

"...we do not discriminate... we never distinguished them from getting APCs if they were properly employed..." (P1)

“... opportunities are given to all races... For performance appraisals, for example, even though the ratings are based on performance, we will ensure all races get the chances...” (P2)

"As far as I am concerned, we do not encounter complicated issues of unity because we treat them well and we treat all equal. We have never distinguished ourselves... we have made a room for our own religious practices..." (P5)

"...principals are fair in treating people regardless of race, trust and rationality... In terms of APC... principals strive to avoid issues... involving all races..." (PK1)

“...in assigning job, even for teachers' club, all races must be involved... in meetings or programs we implement, principals emphasize, regardless of race... For APC, principals try to avoid issues. Involve all people... principals always being fair... in treating people regardless of race..." (PK3) 
Equal opportunities are also given to students to participate in school activities. This is based on the P2, P3, and PK1 statements:

“...opportunities are given to all races... We give all students opportunity to get what they want... In choosing students to take courses or participate in activities, I said give other students opportunities too." (P2)

"MOE guidelines give priority to the integration of the various races... choral speaking, we set must involve all races... last year there was a co-curricular camp... student selected comprised of all three major races..." (P3) "...principals are fair in treating people regardless of race, trust and rationality ... to students ... principals give the same opportunities..." (PK1)

Equal rules and regulations are also imposed in assessing and taking disciplinary action, as said by P6 and PK2: "We use the same assessment... in terms of justice... the same treatment... in the case of student misconduct... we treat the same... following SOP... regardless of background...” (P6)

"...Our discipline teacher is Iban, but there are also Malays and Chinese teacher. We can see that when the punishment is in accordance with the school rules... all students who make the mistake will receive the same punishment. We manage not to be racist... but to be fair to everyone..." (PK2)

For religious school, the opportunity to study in school is open to all races as long as they are Muslims (as the prerequisite to enter the school is the students must be Muslims). This is based on P4 explanation:

"...we don't distinguish between races. When it comes to this school, we have multiracial... there are Iban teachers, there are Chinese teachers... I emphasize that we are no different...One of the subjects preferred language is Chinese... so teach Malay to speak Chinese... As religious school we accept all students regardless of race... as long as they are Muslim, even Bidayuh... for the teachers, we have multiracial." (P4)

The fairness is also can be seen in assigning job and in celebrating teachers and students' big day. This conclusion is based on PK4 statement:

"I see in terms of job, whatever race, any religion...if he sees that the teachers have the potential, he will give the responsibility to them... and we celebrate the success of any teachers and students... students are given a birthday cake, all the teachers and students regardless of race..." (PK4)

\section{Discussion/Analysis}

The findings of this study support Lee's opinion [37] that all Malaysians should be fluent in Malay language. Therefore, school leaders practice to promote unity through the usage of national language is a good practice and must be proceed. This is also conjunction with Sabariah's [38] recommendations that unity could be promoted through interactions among multiracial members of society using a language that can be understood by all. The interaction is necessary therefore they will know and learn more about each other differences and will lead to precautions to avoid sensitive issues in their undertakings. As proposed by the Penang State Consultative Goodwill Council [39], sensitive issues involving politics and religion that not to be touched in any discussions will promote unity. Practices of school leaders to remind and explain about the important of unity during school gathering and meeting in order to strengthen unity is supporting Penang State Consultative Goodwill Council [39] opinion, which stated that the spirit of unity must be instilled constantly in all programs such as football competitions, walkathons, seminars and other events in which multi-races could take part. This finding is also similar to what has been claimed by [38] that, besides good conduct, integrity, ethics and honesty (National Principles or Rukun Negara), involving all races in implementing programs will ensure unity. School leaders' practices that is celebrating all festivals in school in order to strengthen unity is supporting Lee's opinion [37] that festive seasons could lead to a true message of unity to all Malaysians. It is true that during festive seasons, all Malaysians will be united, forget their differences, and in facts give more focus on appreciating differences among them. School leaders' practices in strengthening unity by being fair and giving equal opportunity to all races is in accordance with Yeoh who stated that national harmony could be further enhanced if the policies are fair, and just [40]. This finding also confirms the theory that fairness must be possessed in order to manage differences which could lead to higher ability to manage differences which is one of the elements to unite.

\section{Conclusion}

This study has successfully explored the unity leadership practices among the school leaders in Malaysia. Based on the findings, it can be concluded that school leaders have not yet do the practices at their utmost to promote unity. They need to be given more courses and training to enable them to understand better the values and elements of unity as listed in Unity Model for Teachers and Students [13]. Knowledge and skills of school leaders need to be increased to ensure that their practices in strengthening teachers and students' ability to accept, respect, and manage differences can be increased. This finding also implies that school leaders are not yet fully aware or not fully exposed to the Unity Model for Teachers and Students [13]. This also indicate that the Malaysia Ministry of Education through Aminuddin Baki Institute needs to provide more courses and training to help school leaders to understand better the unity model and their roles to strengthen unity.

This study also supports the Model (refer to Figure 1), showing that teachers and students must possess the 10 
values of unity in order to enhance their ability to accept, respect and manage differences that will ultimately enhance unity. Other implications are school leaders must uphold the policy that as a national language and the language for unity, Malay language must be fluent by all Malaysian. This study also found that most of the school leaders do not aware of other educational policy to promote unity, such as the policy of using the same curriculum and examination in all school, empowering national schools and the implementation of the vision schools. Therefore, it is recommended that school leaders should undergo relevant training to improve their role as a leader to forge unity.

\section{Limitations And Study Forward}

This study however has limitations that it only involved school leaders themselves for the data collection through interview. Based on the present analysis, the researchers recommend several studies to be conducted in the future. Some school leaders were approached but they felt reluctant to be the respondents of this study. Teachers and students' opinion have not been asked in this study, therefore, further research should be done to get views from teachers and students as well. The reasons behind certain schools' leaders' reluctance to participate in unity program should be explored.

The other limitation is this study employed qualitative approach, therefore, further studies to see the level of relationships between school leaders' practices and level of unity among teachers and students based on quantitative data could be done in the future.

Further research should also be embarked to explore the factors that contribute to the low level of unity. Additionally, similar studies could be replicated in other spheres of working institutions.

\section{Acknowledgement}

This research was funded by Universiti Kebangsaan Malaysia (Project No: GG-2019-041, Project No: GGPM2018-071, and Project No: PP-FPEND-2020, Project No: GG-2020-015)

\section{References}

[1]. Wikipedia, Unity in diversity. https://en.wikipedia.org/wiki/Unity_in_diversity; 1 September 2020.

[2]. Akkerman, S. Admiraal, W. \& Simons R.J. (2012). Unity and diversity in a collaborative research project. Culture \& Psychology, 18(2), 227-252. DOI:10.1177/1354067x11434835

[3]. Brooks, J. \& Watson T. (2018). School leadership and racism: An ecological perspective. Urban education. 54 (5),1-25.

[4]. Brooks, M.C. \& Sungtong, E. (2016). We still have bombings': school principals and insurgent violence in Southern Thailand. International Journal of Leadership in Education. 19(5), 505-533.

[5]. Stone, J. \& Rizova, P. (2014). Racial conflict in global society. John Wiley \& Sons

[6]. Miller, A. Ways to Promote Unity. (2017). https://bizfluent.com/info-12140705-ways-promoteunity.html. September 26.

[7]. Educational Researcher. (2014); 43(6), 273-292.

[8]. Bush, T. \& Glover, D. (2016) School leadership and management in South Africa: Findings from a systematic literature review. International Journal of Educational Management. 30(2), 1-27.

[9]. Steyn, G.M. \& Singh, G.D. (2017) Managing bullying in South African secondary schools: A case study. International Journal of Educational Management. 32(6), 1029-1040.

[10]. Hussein, A. \& Haneza, A.H. (2017). Pengurusan pembangunan konsep perpaduan dalam kalangan pelajar sekolah menengah kebangsaan satu kajian di Klang, Selangor. JuPiDi: Jurnal Kepimpinan Pendidikan, 2(4), 1-15.

[11]. Department of National Unity and National Integration. Annual Report 2018. Putrajaya; 2018.

[12]. Mohd Radzi, I. \& Bity Salwana, A. (2020). Statistical measurement on principal practices and student unity level in secondary school. Proceedings Malaysia International Convention on Education Research \& Management (MICER), 261-266.

[13]. Malaysian Ministry of Education. (2014). Education development plan report 2013-2025. Putrajaya: Malaysian Ministry of Education.

[14]. Malaysian Ministry of Education. (2015). Education development plan report 2013-2025. Putrajaya: Malaysian Ministry of Education.

[15]. Malaysian Ministry of Education. (2016). Education development plan report 2013-2025. Putrajaya: Malaysian Ministry of Education.

[16]. Malaysian Ministry of Education. (2017). Education development plan report 2013-2025. Putrajaya: Malaysian Ministry of Education.

[17]. Demie, F. (2003). Raising the achievement of Black Caribbean pupils in British schools: unacknowledged problems and challenges for policy makers. London Review of Education. 1(3), 229248. DOI:10.1080/1474846032000146785

[18]. Pollock, K. \& Briscoe, P. (2019). Schools principals understanding of student difference and diversity 
and how these understandings influence their work. International Journal of Educational Management. 34(3), 518-534.

[19]. Shamsul Amri, B. (2012). Kesepaduan dalam kepelbagaian: perpaduan di Malaysia sebagai work-inprogress. Bandar Baru Bangi: Universiti Kebangsaan Malaysia.

[20]. Vinesh, N. (2017). How to create a legacy of disunity at the workplace. https://leaderonomics.com/business/unity-leadership.

[21]. Sergiovanni, T.J. (1996) Leadership for the schoolhouse: How is it different? Why is it important? San Francisco: Jossey-Bass, Inc. Publishers.

[22]. Bity Salwana A., Rosli I, Shamsudin M, Young M, Zaini A, Ura P., Nasithah A.H., Selvarajah, M. Kasmah, A.B., Nor Suhara F., Nuzulharlina, A.R. \& Akbariah, M. M. (2017). Unity level measurement study. Journal of Educational Research. 18, 13-19.

[23]. Yukl, G. (2013). Leadership in organizations (7th ed.). New Jersey: Prentice Hall.

[24]. Hughes, C. Copeland, S. Agran, M. Wehmeyer, M. Rodi, M.S., \& Presley, J. (2002). Using selfmonitoring to improve performance in general education high school classes. Education and Training in Mental Retardation and Developmental Disabilities, 37, 262-272.

[25]. Harris, A., Day, C., Hadfield, M., Hopkins, D., Hargreaves, A. \& Chapman, C. (2014). Effective leadership for school improvement. New York: RoutledgeFalmer.

[26]. Enizahura, A.A. (2019). Memperkasa Perpaduan. http://www.ikim.gov.my/newwp/index.php/2019/09/23/empowering-unity/.

[27]. Mohamed, B, (2019). National Muhibbah Council needed to promote unity. https://www.nst.com.my/news/nation/2019/08/510247/national-muhibbah-council-needed-promoteunity;

[28]. Abu Bakar, N. (2001). Fundamentals of educational assessment. Tanjong Malim: Universiti Pendidikan Sultan Idris.

[29]. Zikmund, W.G. (2003). Sample designs and sampling procedures: Business research methods. $8^{\text {th }}$ Ed. Mason, OH: Thomson/South-Western.

[30]. Lee, H.S., How to forge National Unity. https://www.malaysiakini.com/letters/283936; December 19 2014.

[31]. Sabariah, M.S., Memastikan keamanan dan perpaduan. https://www.nst.com.my/opinion/columnists/2018/01/324626/ensuring-peace-and-unity; January 13 2018.

[32]. Yeoh, M, Promoting national unity harmony. https://www.thestar.com.my/opinion/letters/2019/11/15/promoting-national-unity-and-harmony.

November 15; 2019.

[33]. Sanadi AR, Caulfield DF, Jacobson RE, Rowell RM. Renewable agricultural fibers as reinforcing fillers in plastics: Mechanical properties of kenaf fiber-polypropylene composites. Industrial \& Engineering Chemistry Research. 1995 May;34(5):1889-96.

[34]. Mohanty AK, Misra M, Drzal LT, editors. Natural fibers, biopolymers, and biocomposites. CRC press; 2005 Apr 8.

[35]. Faruk O, Bledzki AK, Fink HP, Sain M. Biocomposites reinforced with natural fibers: 2000-2010. Progress in polymer science. 2012 Nov 1;37(11):1552-96.

[36]. Baeurle SA, Hotta A, Gusev AA. On the glassy state of multiphase and pure polymer materials. Polymer. 2006 Aug 9;47(17):6243-53.

[37]. Sinha R. Outlines of polymer technology: manufacture of polymers. PHI Learning Pvt. Ltd.; 2004 Oct 1.

[38]. Mohammad NA. Synthesis, characterization and properties of the new unsaturated polyester resins for composite applications. MARA University of Technology. 2007 Apr:45-56.

[39]. Iijima T, Tochimoto T, Tomoi M. Modification of epoxy resins with poly (aryl ether ketone) s. Journal of applied polymer science. 1991 Nov 5;43(9):1685-92.

[40]. Thakur S, Chaudhary J, Sharma B, Verma A, Tamulevicius S, Thakur VK. Sustainability of bioplastics: Opportunities and challenges. Current opinion in Green and Sustainable chemistry. 2018 Oct 1;13:6875.

[41]. Kuruppalil Z. Green plastics: an emerging alternative for petroleum-based plastics. Int J Eng Res Innov.

[42]. 2011;3(1):59-64.

[43]. Sundarraj AA, Ranganathan TV. A review on cellulose and its utilization from agro-industrial waste. Drug Invent. Today. 2018 Jan 1;10(1):89-94.

[44]. Fortea-Verdejo M, Bumbaris E, Burgstaller C, Bismarck A, Lee KY. Plant fiber-reinforced polymers: where do we stand in terms of tensile properties?. International Materials Reviews. 2017 Nov $17 ; 62(8): 441-64$.

[45]. Gurunathan T, Mohanty S, Nayak SK. A review of the recent developments in biocomposites based on 
natural fibers and their application perspectives. Composites Part A: Applied Science and Manufacturing. 2015 Oct 1;77:1-25.

[46]. Sanjay MR, Madhu P, Jawaid M, Senthamaraikannan P, Senthil S, Pradeep S. Characterization and properties of natural fiber polymer composites: A comprehensive review. Journal of Cleaner Production. 2018 Jan 20;172:566-81.

[47]. Dittenber DB, GangaRao HV. Critical review of recent publications on use of natural composites in infrastructure. Composites Part A: applied science and manufacturing. 2012 Aug 1;43(8):1419-29.

[48]. Pickering KL, Efendy MA, Le TM. A review of recent developments in natural fiber composites and their mechanical performance. Composites Part A: Applied Science and Manufacturing. 2016 Apr 1;83:98-112.

[49]. Shubhra QT, Alam AK, Quaiyyum MA. Mechanical properties of polypropylene composites: A review. Journal of thermoplastic composite materials. 2013 Apr;26(3):362-91.

[50]. Langhorst AE, Burkholder J, Long J, Thomas R, Kiziltas A, Mielewski D. Blue-agave fiber-reinforced polypropylene composites for automotive applications. BioResources. 2018;13(1):820-35.

[51]. Fuentes CA, Brughmans G, Tran LQ, Dupont-Gillain C, Verpoest I, Van Vuure AW. Mechanical behaviour and practical adhesion at a bamboo composite interface: Physical adhesion and mechanical interlocking. Composites Science and Technology. 2015 Mar 10;109:40-7.

[52]. Thomason JL. Dependence of interfacial strength on the anisotropic fiber properties of jute reinforced composites. Polymer Composites. 2010 Sep;31(9):1525-34.

[53]. Thomason J, Jenkins P, Yang L. Glass fiber strength-A review with relation to composite recycling. Fibers.

[54]. 2016 Jun;4(2):18.

[55]. Akampumuza O, Wambua PM, Ahmed A, Li W, Qin XH. Review of the applications of biocomposites in the automotive industry. Polymer Composites. 2017 Nov;38(11):2553-69.

[56]. Ishikawa T, Amaoka K, Masubuchi Y, Yamamoto T, Yamanaka A, Arai M, Takahashi J. Overview of automotive structural composites technology developments in Japan. Composites Science and Technology. 2018 Feb 8;155:221-46.

[57]. Koronis G, Silva A, Fontul M. Green composites: A review of adequate materials for automotive applications.

[58]. Composites Part B: Engineering. 2013 Jan 1;44(1):120-7.

[59]. Ahmad F, Choi HS, Park MK. A review: natural fiber composites selection in view of mechanical, light weight, and economic properties. Macromolecular materials and engineering. 2015 Jan;300(1):10-24.

[60]. Khalfallah M, Abbès B, Abbès F, Guo YQ, Marcel V, Duval A, Vanfleteren F, Rousseau F. Innovative flax tapes reinforced Acrodur biocomposites: a new alternative for automotive applications. Materials \& Design. 2014 Dec 1;64:116-26.

[61]. Kong C, Lee H, Park H. Design and manufacturing of automobile hood using natural composite structure.

[62]. Composites Part B: Engineering. 2016 Apr 15;91:18-26.

[63]. Badji C, Beigbeder J, Garay H, Bergeret A, Benezet JC, Desauziers V. Exterior and under glass natural weathering of hemp fibers reinforced polypropylene biocomposites: Impact on mechanical, chemical, microstructural and visual aspect properties. Polymer Degradation and Stability. 2018 Feb 1;148:10416. 